\title{
Limites e desafios das organizações de catadores: uma análise da ASMARE
}

\author{
Limits and challenges of waste picker organizations: an analysis by ASMARE
}

Límites y desafíos de las organizaciones de recolectores: un análisis del ASMARE

\author{
Romário Rocha Sousa ${ }^{1}$ \\ Rafael Diogo Pereira ${ }^{1}$ \\ Daniel Calbino ${ }^{2}$
}

Recebido em 19/02/2019; revisado e aprovado em 13/01/2020; aceito em 26/02/2020 DOI: http://dx.doi.org/10.20435/inter.v22i2.2404

Resumo: A última década registrou o significativo aumento de empreendimentos coletivos de materiais recicláveis. Em Belo Horizonte, a ASMARE, vista como uma experiência pioneira, tornou-se referência na articulação de novas organizações. Contudo crises econômicas e alternâncias governamentais impactaram a organização. Neste sentido, este artigo tem o objetivo de analisar a trajetória da ASMARE, evidenciando os limites e os desafios enfrentados em seu processo histórico de lutas e resistência. Em termos metodológicos, a abordagem qualitativa adotada englobou a realização de entrevistas semiestruturadas e a Análise de Conteúdo para a apreciação dos dados. Os resultados evidenciaram que a Associação enfrenta uma crise que não se restringe aos aspectos financeiros, uma vez que suas implicações têm impactado negativamente a formação política dos associados. Embora a cadeia de reciclagem brasileira seja reconhecida e admirada, contando com a atuação de várias empresas, associações e cooperativas, muitas vezes são os empresários e atravessadores que mais se beneficiam a partir de um ciclo vicioso de exploração do trabalho precarizado dos catadores. A trajetória de luta dos membros da ASMARE representa um importante marco para a história do movimento de catadores no Brasil, porém se depara com o constante desafio de sustentar as ações coletivas em uma sociedade marcada pela desigualdade e exclusão.

Palavras-chave: catadores de materiais recicláveis; cooperativas; ASMARE.

Abstract: The past decade has seen a significant increase in collective ventures of recyclable materials. In Belo Horizonte, ASMARE, seen as a pioneering experience, has become a reference in the articulation of new organizations. However, economic crises and governmental alternations impacted the organization. In this sense, the article aims to analyze ASMARE's trajectory, highlighting the limits and challenges faced in its historical process of struggles and resistance. In methodological terms, the qualitative approach adopted encompassed the performance of semi-structured interviews and Content Analysis to assess the data. The results showed that the Association faces a crisis that is not restricted to financial aspects since its implications resonate in the political formation of its members. Although the Brazilian recycling chain is recognized and admired, with the participation of several companies, associations, and cooperatives, it is often the entrepreneurs and middlemen who benefit most from a vicious cycle of exploitation of the precarious work of collectors. The struggle trajectory of ASMARE members represents an important milestone in the history of the waste pickers' movement in Brazil; however, it comes up against the constant challenge of sustaining collective actions in a society marked by inequality and exclusion.

Keywords: waste pickers; cooperatives; ASMARE.

Resumen: La última década ha visto un aumento significativo en las empresas colectivas de materiales reciclables. En Belo Horizonte, ASMARE, visto como una experiencia pionera, se ha convertido en una referencia en la articulación de nuevas organizaciones. Sin embargo, las crisis económicas y las alternancias gubernamentales afectaron a la organización. En este sentido, el artículo tiene como objetivo analizar la trayectoria de ASMARE, destacando los límites y desafíos enfrentados en su proceso histórico de luchas y resistencia. En términos metodológicos, el enfoque cualitativo adoptado abarcó el desempeño de entrevistas semiestructuradas y análisis de contenido para evaluar los datos. Los resultados mostraron que la Asociación enfrenta una crisis que no se limita a los aspectos financieros, ya que sus implicaciones resuenan en la formación política de sus miembros. Si bien la cadena brasileña de reciclaje es reconocida y admirada, con la participación de varias empresas, asociaciones y cooperativas, a menudo son los empresarios e intermediarios los que más se benefician de un círculo vicioso de explotación del precario trabajo de los recolectores. La trayectoria de lucha de los miembros de ASMARE representa un hito importante en la historia del movimiento

\footnotetext{
${ }^{1}$ Universidade Federal de Minas Gerais (UFMG), Belo Horizonte, Minas Gerais, Brasil.

2 Universidade Federal de São João del-Rei (UFSJ), São João del-Rei, Minas Gerais, Brasil.
} 
de recicladores en Brasil, sin embargo, se enfrenta al desafío constante de mantener acciones colectivas en una sociedad marcada por la desigualdad y la exclusión.

Palabras clave: catadores de materiales reciclables; cooperativas; ASMARE.

\section{INTRODUÇÃO}

A Associação dos Catadores de Papéis, Papelão e Material Reaproveitável (ASMARE), primeira associação de catadores do Estado de Minas Gerais, foi criada em 1 o de maio de 1990, por catadores, com apoio da Pastoral da Rua da Igreja Católica, do poder público e de movimentos sociais.

Os catadores de materiais recicláveis acabam por assumir um papel socioambiental importante para as cidades; ressalta-se, contudo, que a condição do catador é ainda precária e socialmente estigmatizante. Além disso, historicamente, o processo de organização dos catadores foi marcado por conflitos e disputas variadas. Por um lado, são vistos como agentes ambientais que dão outro significado e destino para o lixo das metrópoles, por outro lado, representam o elo mais fraco da cadeia de recicláveis, devido às condições indignas de trabalho e aos parcos ganhos econômicos obtidos com a atividade, uma vez que, geralmente, são os atravessadores que mais se beneficiam na cadeia produtiva da reciclagem.

Pelo seu crescimento e relativo sucesso, a ASMARE tem sido vista por muitos como modelo para a criação de outros empreendimentos associativos de catadores. Apesar da importância dessa associação no desenvolvimento de ações sociais e na luta pelo reconhecimento de seus direitos, após um longo histórico de atuação e conquistas, a associação passa por uma fase de crise.

As recentes mudanças na conjuntura política, marcada pelo avanço de bandeiras conservadoras, bem como a recessão econômica dos últimos anos, têm afetado a sua dinâmica organizacional. É neste contexto que aqui se propõe como objetivo geral: analisar a trajetória da ASMARE, evidenciando os limites e os desafios enfrentados pelos membros dessa associação em seu processo histórico de lutas e resistência.

Ainda que se trate de um caso único, o peso histórico da organização no movimento nacional de catadores a coloca como um fenômeno singular do ponto de vista analítico. Ademais, a literatura existente, que aborda a ASMARE (JACOBI; TEIXEIRA, 1997; DIAS, 2002; TORRES, 2008), não lidou com os atuais limites e desafios da organização. Assim, o presente trabalho pode trazer reflexões relevantes para as demais organizações do setor e trazer novas reflexões para o movimento.

\section{BREVE HISTÓRICO DAS ORGANIZAÇÕES DE CATADORES NO BRASIL}

Desde os anos de 1960, várias experiências, amparadas pelas pastorais da Igreja Católica, organizações não governamentais e universidades, têm buscado a aproximação com catadores e moradores de rua (SANT'ANA; MAETELLO, 2016). Ao longo das décadas seguintes, iniciativas como associações e cooperativas de catadores formaram-se no Brasil, sendo muitas apoiadas por governos locais, por meio de programas de coleta seletiva (PEREIRA; TEIXEIRA, 2011).

A organização desses trabalhadores ganhou mais visibilidade a partir de 1999, por meio do Movimento Nacional de Catadores de Materiais Recicláveis³ (MNCR). Além dos próprios

\footnotetext{
${ }^{3}$ Para mais informações, acesse: www.mncr.org.br.
} 
catadores, diversos atores estão envolvidos, como indústrias, consumidores, organizações da sociedade civil e poder público (BARTOLI, 2013). Contudo são os catadores os principais agentes que têm se organizado, desde o final da década de 1980 (PEREIRA; TEIXEIRA, 2011).

Os catadores de materiais recicláveis são uma categoria de trabalhadores em crescimento. Entre os anos de 1999 e 2004, o número aumentou de 150 mil para 500 mil (BARTOLI, 2013). Estima-se, a partir dos dados divulgados pelo Movimento Nacional de Catadores, que há cerca de 1 milhão de catadores no país (MAGALHÃES, 2016). Ainda que não haja um recenseamento exato dos catadores, é expressiva a quantidade de pessoas que sobrevivem do trabalho da coleta de materiais recicláveis. Nas últimas décadas, o setor de reciclagem tem demonstrado um crescimento considerável, em virtude de fatores como: necessidade de maximização dos recursos, inovações tecnológicas e aumento do consumo. O catador participa desse processo quando reconhece sua realidade e busca formas de se organizar. Nesse sentido, a atuação não é só um exercício de sobrevivência, mas também de luta por melhores condições de vida (COSTA; PATO, 2016).

Do ponto de vista da caracterização das organizações dos catadores, há registros de que os empreendimentos coletivos começaram no início da década de 1980, apesar de a maior parte ter sido criada recentemente. Estima-se que mais da metade $(56,5 \%)$ das associações e cooperativas de catadores de materiais recicláveis surgiu a partir de 2005 (IPEA, 2017).

Em relação à distribuição espacial dos catadores, há registros em 4.961 municípios, o que representa quase $90 \%$ dos municípios brasileiros. A maior parte se concentra na Região Sudeste, o que corresponde a aproximadamente $42 \%$ do total, ou 160.000 catadores (IPEA, 2013).

Da mesma forma, a Região Sudeste representa quase $50 \%$ do total de cooperativas e associações, seguida pela Região Sul, com 28\%. Uma hipótese factível para tal concentração referese ao fato de essas regiões concentrarem os principais centros urbanos do país e produzirem maiores quantidades de lixo e, consequentemente, de materiais recicláveis.

Contudo um dado que chama a atenção é que o percentual de associativismo entre os catadores é de apenas 10\%, enquanto os outros $90 \%$ atuam de forma independente, trabalhando para negócios de sucata (BRAGA; MACIEL, 2018). Do total desses empreendimentos, grande parte atua na informalidade (40,3\%), enquanto as associações representam $31,3 \%$, e as cooperativas, 28,3\% do restante. Essas organizações, em 2017, tinham 15.732 associados, sendo a maioria formada por mulheres (59,9\%). Mesmo assim, mais da metade das associações e cooperativas não excede 20 membros. Além disso, apenas 3,2\% delas têm mais do que 100 associados (IPEA, 2017).

\section{POLÍTICAS DE GESTÃO DE RESÍDUOS E IMPACTOS NA RECICLAGEM}

Na busca pela superação das limitações estruturais, os empreendimentos coletivos de catadores se apresentam como uma estratégia para o fortalecimento das relações entre os envolvidos. Entre as vantagens: agrega mais valor ao material recolhido, eleva o poder de barganha do preço do material, fortalece as negociações com o poder público, empresas, parceiros e, principalmente, aumenta a capacidade de mobilização política na luta por melhorias nas condições de trabalho (IPEA, 2013).

Entre as conquistas, no ano de 2002, a Classificação Brasileira de Ocupações (CBO) reconheceu como profissão a atuação de catador, sendo um marco importante na promoção de uma maior visibilidade das ações dos catadores na sociedade. Da mesma forma, a aprovação 
da Lei da Política Nacional de Resíduos Sólidos, Lei 12.305/2010, fortaleceu as cooperativas de reciclagem, dando maior visibilidade à atuação. Contudo, se, por um lado, o poder público destaca o papel central que os catadores têm no processo de reaproveitamento do material, por outro, o baixo valor da remuneração recebida e as adversas condições de trabalho resvalam em desafios substanciais (FERRAZ; MUELLER, 2013).

Para Bartoli (2013), há uma fronteira tênue entre os interesses dos catadores, construídos nas lutas sociais, e os interesses dos empresários na indústria da coleta do lixo urbano. Portanto o mercado da reciclagem oferece a oportunidade para os catadores se organizarem por melhores condições de trabalho, no entanto reproduz também os interesses da indústria da reciclagem. A figura a seguir representa, de maneira resumida, o fluxograma da cadeia de reciclagem, mostrando as principais relações entre os atores envolvidos.

Figura 1 - Fluxograma da cadeia de reciclagem

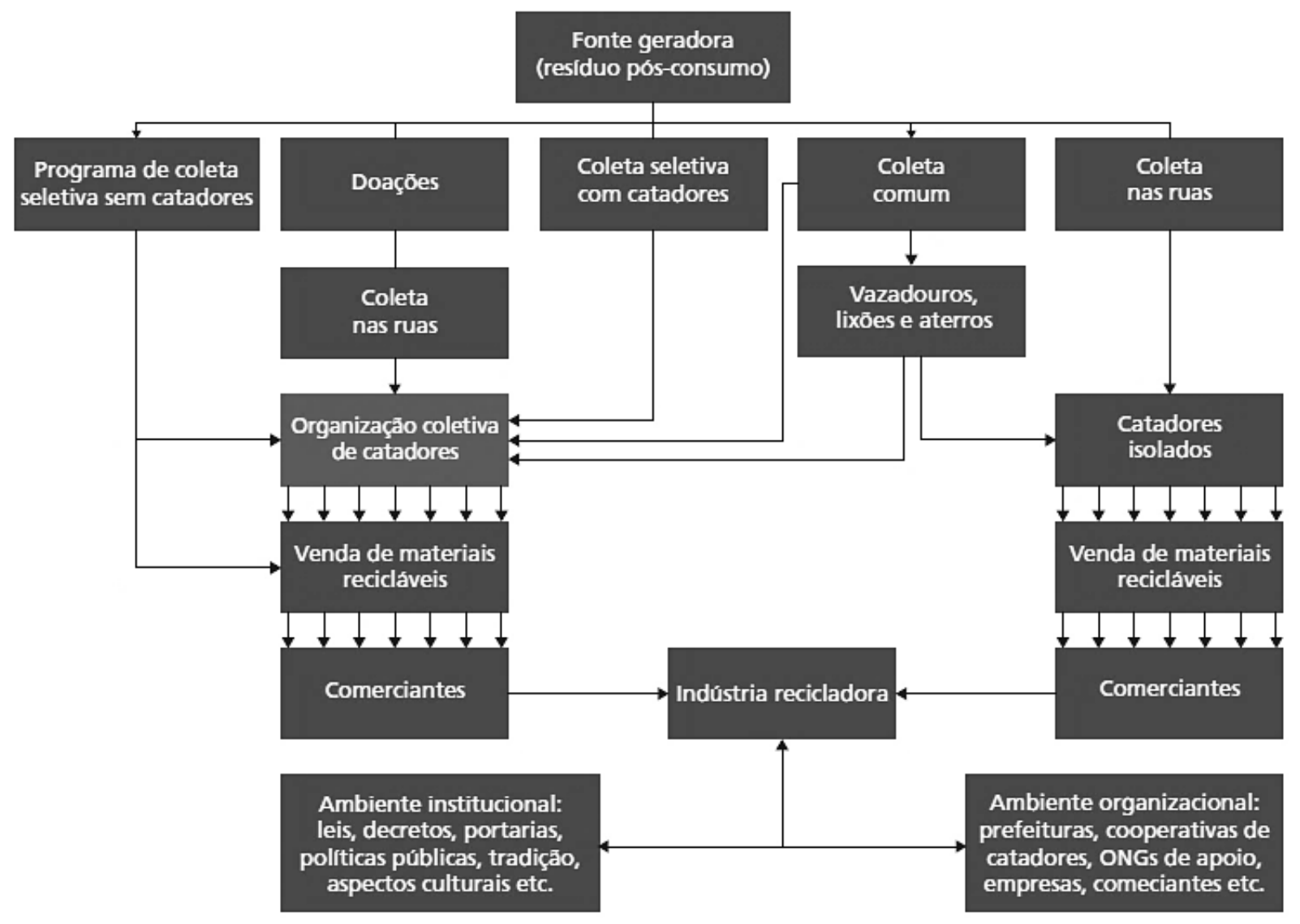

Fonte: IPEA (2013).

Apesar de a cadeia produtiva brasileira ser admirada com a atuação de várias empresas, associações e cooperativas, muitas vezes são os empresários que mais se beneficiam a partir de um ciclo vicioso de exploração do trabalho (BAPTISTA, 2015). Pereira e Teixeira (2011) corroboram esse argumento ao apontarem que os proprietários das empresas de reciclagem englobam os grandes lucros, valendo-se do discurso da responsabilidade socioambiental para escamotear a necessidade de repensar o consumo e a mudança nas condições de trabalho dos catadores.

A gestão de resíduos sólidos no Brasil tem sido considerada limitante em termos de soluções práticas, devido ao pouco beneficiamento e à incidência de catadores informais nas 
ruas. O Brasil é um dos países que mais reciclam materiais (em termos de quantidade), contudo a maior parte do material que é recolhido para este fim vem do trabalho de catação (TORRES, 2008). Os catadores são os grandes responsáveis por $90 \%$ de todo o material que é reciclado no país (IPEA, 2017).

Apesar de a reciclagem não ser um assunto novo, esbarra ainda em muitas dificuldades para a sua efetivação. Segundo dados da CEMPRE (2015), apenas 13\% dos resíduos urbanos gerados no país são reciclados. Além disso, dos 5.570 municípios do Brasil, 927 realizam coleta seletiva, com $28 \%$ da população atendida por esse serviço de coleta.

Interessante observar que, apesar da destinação adequada de resíduos ser temática na agenda governamental desde os anos de 1980, os programas de coleta seletiva são pouco eficientes. Segundo o IPEA, apenas $2,4 \%$ das coletas são realizadas de forma seletiva, o restante ocorre de maneira tradicional, em que o lixo é usualmente compactado sem a separação do que pode ser reaproveitado, o que dificulta a reciclagem (IPEA, 2013). Por sua vez, os baixos índices relativos à coleta seletiva se devem aos entraves que envolvem aspectos sanitários, ambientais e administrativos.

Ademais, enquanto a terceirização é um instrumento "estratégico" para muitas gestões, ela revela uma falha comum nos programas de coleta seletiva. Geralmente, empresas terceirizadas são pagas de acordo com a quantidade e o volume de material recolhido. Assim, conflitos de interesses emergem, pois, para a empresa contratada, incentivar a redução de lixo é desfavorável aos seus interesses econômicos. Além disso, para a efetivação da reciclagem, é preciso um processo de triagem que exige a manutenção das melhores condições possíveis do material coletado. Contudo o que se observa é que a maioria das empresas faz o uso de caminhões compactadores para realizar a coleta, o que dificulta ou, até mesmo, inviabiliza a reciclagem.

\section{METODOLOGIA}

A presente pesquisa se caracterizou pela abordagem qualitativa, pautada pela perspectiva de Gonzalez Rey (2005), que defende o caráter construtivo-interpretativo do conhecimento. Ou seja, parte-se da noção de que o conhecimento é uma construção, uma produção humana, e não algo que está pronto e ordenado de acordo com categorias universais do conhecimento (GONZALEZ REY, 2005).

Em relação às fontes, elas foram divididas em primárias e secundárias. As fontes primárias estão representadas por entrevistas, observações e documentos internos disponibilizados pela associação. Por sua vez, as fontes secundárias englobam dados setoriais, reportagens e trabalhos acadêmicos produzidos sobre a ASMARE.

No que diz respeito à coleta de dados, foram realizadas entrevistas amparadas por um roteiro semiestruturado, coletando, entre os meses de outubro e dezembro de 2017, nove relatos orais. Apesar do longo tempo de vínculo com a organização, apenas dois dentre os nove entrevistados estavam presentes no momento da fundação da ASMARE. Na data da pesquisa, a maioria dos que fizeram parte da fundação e da construção da associação já havia se aposentado ou falecido.

A seguir, é apresentada a relação dos entrevistados, ilustrando o tempo de trabalho que cada um acumulava na associação (Quadro 1) até a data da coleta das entrevistas. O estudo recebeu a autorização formal da associação de catadores e respeitou os critérios éticos da 
instituição pesquisada. Além disso, adotou-se o critério de confidencialidade, utilizando nomes fictícios para representar os sujeitos de pesquisa nos excertos das entrevistas reproduzidos na análise.

Quadro 1 - Relação dos(as) catadores(as) e o tempo de trabalho na ASMARE

\begin{tabular}{|c|c|c|}
\hline Catador(a) & Nome fictício & Tempo de trabalho na associação (em anos) \\
\hline 01 & Rosária & 15 \\
\hline 02 & Joaquim & 18 \\
\hline 03 & Antônio & 28 \\
\hline 04 & Maria de Fátima & 28 \\
\hline 05 & Rita & 05 \\
\hline 06 & Isabel & 17 \\
\hline 07 & Márcio & 07 \\
\hline 08 & Roberto & 11 \\
\hline 09 & José & 22 \\
\hline
\end{tabular}

Fonte: Elaborado pelo autor.

Quanto ao tratamento dos dados, adotou-se a Análise de Conteúdo (AC) (BARDIN, 2004), aqui apreendida como uma técnica auxiliar para organização, tratamento e análise dos relatos coletados. Da mesma forma, na presente pesquisa, o discurso nas falas dos sujeitos foi entendido como recursos linguísticos, dotados de sentidos, significados e articulado às suas condições histórico-culturais de produção social (BRANDÃO, 2002). Nesse sentido, os catadores não podem ser entendidos como sujeitos abstratos em seus discursos, mas situados na história da cidade de Belo Horizonte e na trajetória da ASMARE.

A Análise de Conteúdo levada a cabo compreendeu as três fases propostas por Bardin (2004), a saber: 1) pré-análise, 2) exploração do material e 3) tratamento dos resultados, inferência e interpretação. A fim de dar sequência à análise categorial ou temática, foram estruturados dois eixos de análise, que serão apresentados a seguir. O primeiro, ancorado na análise de documentos e trabalhos publicados sobre a ASMARE, realizou um resgate sucinto de sua trajetória, evidenciando os principais marcos em sua história. Por sua vez, o segundo eixo explorou o contraste entre a fase em que a associação contava com parcerias e maior apoio do poder público e o momento atual, em que enfrenta diversos desafios inerentes à falta de recursos e desmobilização.

\section{RESULTADOS}

\subsection{História da ASMARE e as políticas de resíduos em Belo Horizonte}

Em 1989, a prefeitura de Belo Horizonte desenvolveu as primeiras iniciativas de coleta seletiva, contudo essa política foi trabalhada de maneira tímida e desconsiderou a realidade dos catadores. Na mesma época, um grupo de catadores ocupou uma área que era utilizada como estacionamento. O espaço passou a ser utilizado como moradia das famílias e para armazenar e separar o material coletado nas ruas (TORRES, 2008).

Entretanto, um ano depois, um grupo de policiais e fiscais da prefeitura ateou fogo nos barracões e nos carrinhos dos catadores (CARDOSO, 2003). Após esse ato, ainda marcado na 
lembrança de muitos catadores, membros da Pastoral da Rua interviram e procuraram se informar sobre o acontecido (JACOBI; TEIXEIRA, 1997).

A Pastoral de Rua tinha a ideia de que era preciso organizar a produção dos catadores e lutar pelo reconhecimento do trabalho enquanto categoria profissional (DIAS, 2002). Por meio de articulações políticas, fortaleceram a consciência de que tinham direito, de que eram trabalhadores e poderiam transformar em renda o material coletado. Nasceu, assim, a ASMARE, no dia 1 o de maio de 1990.

No final de 1992, após embates com o poder público, a associação conseguiu seu primeiro galpão de triagem de recicláveis. Em dezembro do mesmo ano, foi assinado um convênio de cooperação entre a Prefeitura de Belo Horizonte, a ASMARE e a Mitra Arquidiocesana, que viabilizou a manutenção do referido galpão. Após a vitória nas eleições de 1992 da Frente Popular (uma coligação de partidos liderada pelo Partido dos Trabalhadores), houve melhoria nas relações entre governo municipal e a população de rua (JACOBI; TEIXEIRA, 1997).

Em 1993, a prefeitura de Belo Horizonte reconheceu, oficialmente, a importância do trabalho do catador na manutenção da limpeza pública e na economia gerada pela coleta, transporte e destinação final do material recolhido. A criação da Lei Orgânica do Município, que deu prioridade na catação de materiais aos catadores, legitimou a atuação.

Assim, foi implantada a coleta seletiva na cidade e criado um convênio que consistia em uma quantia mensal repassada à associação, que era usada para comprar maquinários e equipamentos de trabalho. Segundo relatos dos catadores, o convênio durou até o ano de 2008. A partir de 2009, o recurso foi cortado, numa decisão que foi tomada na gestão de um prefeito com posições políticas conservadoras e distantes dos movimentos sociais.

Ao longo de seus quase trinta anos de história, os membros da ASMARE desenvolveram diversos projetos, por meio de parcerias. Segundo Gonçalves et al. (2002), a Associação teve mais de 80 parcerias estabelecidas com segmentos sociais. Porém, nos últimos anos, tais parcerias se reduziram drasticamente, somando-se à perda do apoio governamental, de forma com que muitos projetos tivessem de ser descontinuados.

$\mathrm{Na}$ busca por alternativas, os associados têm prestado alguns serviços para empresas, instituições, condomínios e eventos. Em troca desses serviços, a ASMARE recebe materiais e doações, o que possibilita uma fonte de renda alternativa para seus associados.

Atualmente, a organização processa, por ano, um total de 3.429 toneladas de materiais recicláveis. No âmbito estrutural, a ASMARE possui duas unidades e tem 140 associados, número que veio se reduzindo ao longo do tempo, já que, na década de 1990, esse número era superior a 260.

Segundo os catadores, um fenômeno que explica a diminuição do número de associados foi o aumento da geração de empregos no país. Durante a época da Copa do Mundo, sediada no Brasil, em 2014, surgiram muitas oportunidades de emprego e vários associados foram trabalhar na indústria. No entanto, passado o momento e com a consequente crise econômica, muitos dos que perderam o emprego acabaram retornando para a associação.

\subsection{Impactos e desafios da ASMARE na conjuntura econômica-política}

Dias (2002), ao escrever uma dissertação sobre a Associação, identificou-a sobre três grandes fases. A primeira (1988-1993) representou o período de luta dos catadores pelo direito 
de trabalhar e a criação da Associação. A fase 2 (1993-1998) marcou a atuação dos catadores em parceria com o poder público e o desenvolvimento de uma política de resíduos sólidos mais integrativa. E a terceira, a partir de 1999, representou a ampliação de atividades e projetos, assim como atuação no nível estadual e nacional.

Esses, provavelmente, tenham sido os "anos dourados", isto é, a fase de maior consolidação da organização. Nesse sentido, uma contribuição deste trabalho e o que o diferencia dos demais é a análise da ASMARE no atual estágio de 2019, o que se pode chamar de uma "quarta fase". Essa última é caracterizada por uma crise, marcada pela redução das parcerias e pelo enfraquecimento da organização.

Há dez anos, a ASMARE possuía uma estrutura administrativa formada por seis comissões. Cada uma delas era composta por cinco associados e um coordenador, que eram eleitos em assembleia. As comissões estavam relacionadas com as atividades, e os projetos eram desenvolvidos na organização, o que se alterou nos últimos anos. Atualmente, a estrutura da Associação está baseada no papel desempenhado pela diretoria, formada por apenas três catadores.

Na mesma época, a Associação oferecia para seus membros diversos benefícios, entre eles: vale-transporte; auxílio-funeral; seguro de vida; convênio com farmácias; fornecimento e manutenção de carrinhos coletores à tração humana. Na percepção de um dos associados:

(1) Antigamente, a gente tinha mais projetos, né? Tinha uniforme. Tinha o décimo terceiro, hoje não tem mais. Isso vai desanimando um pouco, né? Isso prejudica o ambiente de trabalho. Hoje a gente trabalha muito e não vê o resultado disso. A gente esforça muito e acaba não tendo nada. (Rosária).

A falta de parcerias, a mudança na política municipal e o consequente fim do convênio com a prefeitura comprometeram a capacidade de desenvolvendo da organização. Segundo Baptista (2015), organizações formadas por catadores apresentam grandes dificuldades, porque vivenciam um contexto de desamparo estrutural. A relação com políticas públicas são centrais para a sustentabilidade, já que cumprem um papel de serviço público de gestão dos resíduos de forma não remunerada pelos órgãos públicos. Ao considerar-se que uma organização de grande porte e de quase três décadas tem sofrido grande impacto, como as pequenas associações podem minimamente sobreviver sem o elo com políticas públicas locais?

Neste sentido, é possível perceber como uma das catadoras, a Maria de Fátima, tem uma visão ampla sobre coleta seletiva, compreendendo a articulação necessária entre comunidade, Estado e catadores. Ela reconhece que a falta de investimento em políticas de conscientização traz consequências negativas para os catadores.

(2) A falta de investimento em educação pros cidadão gera muitos problemas pro catador. Não adianta o caminhão do lixo passar pelas ruas recolhendo o material das lixeiras, se a população não sabe separar o que é material recicrável daquilo que, de fato, é lixo. Normalmente, de todo o material que o catador já seleciona nos pontos de coleta para trazer para a associação, um terço dele é lixo. Muito material que poderia ser recicrado acaba sendo levado para os aterros sanitários. (Maria de Fátima).

Segundo Silva et al. (2016), a coleta seletiva não pode ser vista como uma etapa isolada na cadeia da reciclagem, pois demanda investimento em educação, nas condições de trabalho e no mercado de compra e venda de materiais. O Estado, enquanto instituição formada por 
representantes da população, não pode se eximir do seu papel responsável pelo desenvolvimento do país. Em um ciclo vicioso, a ausência do Estado no desenvolvimento de políticas públicas para a gestão de resíduos impacta no processo organizacional da associação, restringindo as ações de formação e parcerias:

(3) Hoje a gente não faz isso. Sem o convênio e as parceria, a gente não tem muita opção, né? A gente fazia muita coisa. Tinha o teatro, as oficinas... era chique demais, era lindo! Eu tenho saudade disso. Isso é importante, né? A gente cria consciência e busca ser cidadão. (Maria de Fátima).

O fragmento discursivo (3) retrata o contexto da associação sem o desenvolvimento das atividades educativas e culturais. Baseando-se nos relatos, há uma mudança significativa da forma como os catadores exerceram o seu trabalho, que agora se limita a catar e separar o material. Sem as atividades complementares, há outra questão problemática, a dimensão política. Os projetos educativos e culturais não eram apenas atividades que complementavam a rotina dos catadores; como disse Maria de Fátima, eles tinham sua importância, principalmente, porque ajudavam a desenvolver a consciência política e a busca por cidadania.

Uma atividade que era desenvolvida por alguns membros da associação era o trabalho educativo realizado em escolas da rede pública. Essa ação incentivava a criação de conselhos ambientais e a implementação da coleta seletiva em ambientes escolares, destinando o material reciclável para os catadores.

A atividade tinha como potencial aproximar experiências de vida dos membros com outros sujeitos que poderiam contribuir com possíveis soluções para o problema do lixo. Era uma forma de envolver os cidadãos numa discussão que não dizia respeito apenas aos catadores, mas em articulações importantes entre o trabalho dos catadores e uma formação fundamentada nas necessidades do processo de trabalho.

Outra questão é que, com a falta de parcerias, os esforços dos catadores se concentram no material coletado, porém a variação no preço desse material tem gerado alguns atritos e divisões entre eles, o que prejudica o ambiente de trabalho e a solidariedade entre os membros. Aliado a isso, a associada Rosária relata um problema com o qual a associação tem se deparado ao longo dos últimos anos: a elevação das dívidas. Essas foram geradas, principalmente, por causa das manutenções nos galpões, já que o espaço foi construído há quase trinta anos e necessita de contínua manutenção.

(4) O catador precisa de maquinário e de caminhão, necessitam pintar os box, fazer manutenções na infraestrutura do galpão... A associação já tem mais de vinte e sete anos de existência. Fora os gastos, as dívidas e o salário dos catadores. Como o preço do material é muito baixo, geralmente, na casa de centavos, os catadores precisam vender toneladas de materiais. O fato de muitas empresa já vender ou reciclarem o material que poderia ser doado para a ASMARE também é um limitador. A associação está muito sucateada, como você pode ver. (Maria de Fátima).

A ASMARE necessita de recursos para manter seu patrimônio em condições mínimas de uso. Os efeitos da crise financeira são visíveis para quem adentra no galpão. Falta iluminação, um sistema de fiação adequado, água encanada nos boxes para os catadores beberem, equipamento de proteção individual (EPI), pintura, extintores de combate a incêndios. Nos galpões, percebese ainda muito lixo espalhado pelo chão, além da presença de ratos e de inúmeros mosquitos, elevando o risco de disseminação de doenças. 
O ambiente, muitas vezes insalubre, tem gerado riscos aos catadores e dificultado ainda mais o processo de trabalho dentro do galpão. Talvez, a expressão que mais represente a condição da associação neste momento, como descrito por Maria de Fátima no fragmento, seja o seu sucateamento.

Além dos fatores vinculados à perda de apoio político, o volume de material coletado diminuiu por uma questão de crise econômica, o que impacta na produção, no consumo e no consequente descarte de resíduos. Somando-se a isto, muitas empresas e estabelecimentos comerciais estão vendendo ou reciclando o material que antes era doado para os catadores, conforme enfatizou a cooperada no fragmento (4).

Entre as diversas implicações para a ASMARE, ressalta-se a necessidade de repensar estratégias de aquisição do material reciclável, principal fonte de renda dos catadores. Ademais, a mudança no comportamento dessas empresas é algo que ilustra o momento em que a reciclagem se torna viável financeiramente.

Se, antes, a gestão dos resíduos por parte das empresas não era eficiente, comodamente se utilizava do discurso de responsabilidade ambiental, realizando a doação dos materiais para os catadores. No entanto, transformadas em possibilidades monetárias, as doações diminuíram, colocando, inclusive, outra reflexão: enquanto a lógica do sistema de Economia Mercantil reciclou os trabalhadores de catação na função de agentes ambientais, estariam, agora, sob o risco de serem efetivamente os descartáveis do sistema?

Em relação aos processos internos da organização, por se tratar de uma história de quase 30 anos, a ASMARE enfrenta um desafio identitário relacionado ao processo de transição entre as antigas e novas gerações.

(5) Olha, tem muita falta de interesse por parte de quem está chegando. Porque tá chegando e já pegou tudo mastigado. Porque na época que começamos aqui foi uma grande dificuldade pra chegar onde tá hoje. Na época, quando começamos, foi bem difícil. Então, pra quem está chegando agora, é responsabilidade dos mais velhos de estar passando pra quem tá chegando. E falar: olha, vamo trabalhar assim não, vamos trabalhar dessa forma. Porque se você fizer o material dessa forma ele vai cair de preço, então vamo faze bonitinho pra nós subir. (Antônio).

O problema da ruptura na transmissão dos valores entre as diferentes gerações é reforçado na fala de outros associados, ao destacarem o distanciamento de seus integrantes mais novos, que não chegaram a vivenciar o processo histórico de lutas empreendido pelos mais antigos. $O$ dilema é problematizado pela catadora Maria de Fátima, no fragmento a seguir:

(6) As pessoas que vão chegando à associação não vivenciaram todo aquele processo de resistência para construir a ASMARE. Dessa forma, o que irão valorizar? (Maria de Fátima).

Muito do que foi vivenciado pelos catadores está registrado apenas em suas memórias pessoais, quase não há arquivos ou fotografias que ilustram os momentos históricos e percalços presentes na trajetória da Associação. O recente dilema enfrentado pela ASMARE, talvez, seja um dos primeiros no campo das organizações coletivistas de catadores, já que, pelo seu pioneirismo e longevidade, estão presenciando um processo sucessório entre membros. A entrada de novos associados que não fizeram parte da constituição identitária do grupo e o comprometimento organizacional com os valores coletivos se colocam como desafios para o fortalecimento da organização ${ }^{4}$.

\footnotetext{
${ }^{4}$ Apesar de não tratar da sucessão, o trabalho de Cardozo et al. (2017) ilustra a relevância e os desafios do comprometimento organizacional em cooperativas de catadores.
} 
Diante dos amplos desafios a serem superados, é relevante enfatizar a alternativa utilizada por várias associações e cooperativas de trabalhadores no país: a constituição de redes de apoio. Em Minas Gerais, há experiências expressivas, como a Cooperativa de Reciclagem dos Catadores da Rede Economia Solidária (CATAUNIDOS) ${ }^{5}$.

Criado em 2001, por intermédio da Pastoral da Rua e de outros atores envolvidos, o Instituto Nenuca de Desenvolvimento Sustentável (INSEA) é uma organização não governamental de âmbito nacional, sem fins lucrativos, voltada para a assessoria técnica e parceria junto a grupos comunitários, empresas, ONGs e à Administração Pública. O instituto tem o objetivo de qualificar a assistência técnica junto a catadores de papel e moradores de rua.

A CATAUNIDOS tem o objetivo de promover a melhoria das condições de vida e de trabalho para os catadores. Segundo a instituição, o projeto é formado 450 catadores de materiais recicláveis de nove associações e cooperativas da Região Metropolitana de Belo Horizonte (RMBH). Até o ano de 2012, a rede tinha 25 entidades cooperadas, produzindo um total de 850 toneladas de material reciclável por mês. Atualmente, ela se subdivide em três unidades: a Unidade Metropolitana de Belo Horizonte, a Unidade Centro-Oeste e a Unidade Estrada Real. Essas três unidades contam com trinta e três empreendimentos, 857 associados, estando presentes em 30 municípios de Minas Gerais.

Apesar de a ASMARE ter feito parte da criação da rede CATAUNIDOS, o associado José relata que hoje eles têm uma participação muito pequena na rede. A diminuição da participação dos catadores em reuniões, eventos e encontros coletivos enfraquece o movimento e a atuação política. Mas, ao mesmo tempo, a participação exige que os catadores estejam fora de seus ambientes de trabalho, o que representaria um prejuízo financeiro para alguns deles, como indaga um dos entrevistados no fragmento a seguir:

(7): O catador precisa catar material pra ganhar seu ganha pão. Como ele vai nas reuniões? (José).

Isso revela que, paradoxalmente, participar de uma rede que, em tese, fortalece as relações políticas e econômicas entre os envolvidos, nas atuais condições desses catadores, é um grande desafio, pois o limite de sua necessidade imediata de sobrevivência os colocam em um ciclo perpétuo de trabalho interno.

\section{CONSIDERAÇÕES FINAIS}

Diante do contexto analisado, torna-se evidente que a crise enfrentada pelos membros da ASMARE não é apenas de ordem econômica, pois eles relataram também uma espécie de esvaziamento das práticas políticas, traduzido, entre outros fatores, pela diminuição da militância de seus membros. A falta de apoio e das parcerias, o fim do convênio com a prefeitura e a diminuição do volume de material coletado (em virtude da crise econômica e da própria reciclagem das empresas) têm gerado enormes dificuldades para os associados da ASMARE. Como consequência, quase não há atividades educativas e culturais voltadas para a formação política do grupo. Na mesma lógica, a capacidade de mobilização dos catadores parece estar diminuindo, o que se configuraria como um esvaziamento das práticas políticas e da articulação em redes.

\footnotetext{
${ }^{5}$ Rede Cataunidos. Para saber mais informações, acesse http://www.insea.org.br/projeto-rede-cataunidos ou consulte o trabalho de Silva (2014).
} 
O trabalho árduo da reciclagem, que exige um intercâmbio com a participação dos demais cidadãos, coloca o desafio de os catadores terem de conciliar sua atividade laboral com as demandas sociais e políticas, como as reivindicações diante da não garantia de seus direitos (SILVA, 2014). Isso faz com que o tempo de maturação socialmente necessário para a viabilidade de uma organização coletiva de catadores comece a se tornar incompatível com a rotina diária de trabalho. Isto é, a necessidade de suprir as demandas mais básicas para a própria sobrevivência, muitas vezes, prejudica ou inviabiliza a participação deles nas atividades formativas e políticas que são essenciais para a sustentação dessas organizações.

É válido apontar também para a retórica presente em nossa sociedade, que posiciona o catador de materiais recicláveis como um agente ambiental e que pode, até certo ponto, contribuir para o reconhecimento de sua profissão e gerar reflexões relevantes acerca da gestão de resíduos e educação ambiental. Contudo cabe questionar: até que ponto esse discurso contribui para que os catadores conquistem melhorias reais nas condições de trabalho ou apenas atribui um "ethos ecológico" a uma ocupação que, reiteradamente, submete os sujeitos a uma penosa sina de trabalho? Ou ainda, como justificar uma ocupação sem quaisquer garantias trabalhistas ou apoio do Estado? Estado este que ignora os catadores à mesma medida que se beneficia com o serviço de limpeza pública por eles prestado.

Nesse sentido, ao resgatar a trajetória de uma das mais emblemáticas associações de catadores do Brasil, evidencia-se que mesmo as organizações consolidadas necessitam de um duplo esforço para captar recursos e manter parcerias, além da ininterrupta formação política de seus membros. Afinal, uma iniciativa que seja (ao menos em parte) contra-hegemônica se colocará irremediavelmente num plano perene de disputas, por ousar coexistir com o modelo neoliberal, inconsequente, excludente e desigual reinante.

Por isso, parcerias, programas e políticas públicas que auxiliem na permanência dos catadores no empreendimento e contribuam para a sustentabilidade das cooperativas de catadores são fundamentais, sobretudo em momentos de turbulência econômica e política (IPEA, 2017). É válido lembrar que todo investimento público em cooperativas, tais como a ASMARE, retorna para a sociedade não apenas por meio da geração e manutenção de empregos como também na reafirmação de uma política para o tratamento de resíduos e para a minimização das consequências trágicas do descarte inadequado do lixo, principalmente, em grandes metrópoles.

Por fim, acreditamos que as dificuldades evidenciadas no contexto atual da ASMARE não sinalizam para o seu término, mas para um novo e necessário ciclo de lutas e de reinvenção de suas práticas. Portanto espera-se que o presente trabalho seja apreendido como um convite para se pensar caminhos e alternativas para a significativa constelação de organizações, iniciativas e movimentos presentes em nosso país e que, como a ASMARE, representam a (única) ocupação para milhões de brasileiros, com extrema relevância não apenas econômica, mas também social, cultural e política. Entre as alternativas para o enfrentamento de situações como a da ASMARE, emerge a possibilidade do desenvolvimento e da aplicação de tecnologias participativas. Entretanto, para serem efetivas, essas tecnologias devem nascer articuladas com a realidade social e econômica dos empreendimentos, respeitando o ambiente cultural e a maneira como os catadores se organizam. Nesse sentido, universidades e centros de ensino representam importantes parceiros que podem contribuir por meio da proposição de projetos de pesquisa e extensão, além do fornecimento de conhecimentos científicos, tecnologias e outros saberes. 


\section{REFERÊNCIAS}

BAPTISTA, V. F. As políticas públicas de coleta seletiva no município do Rio de Janeiro: onde e como estão as cooperativas de catadores de materiais recicláveis? Revista de Administração Pública, Rio de Janeiro, v. 49, n. 1, p. 141-64, 2015.

BARDIN, L. Análise de conteúdo. Lisboa: Edições 70, 2004.

BARTOLI, M. A. Processos de organização de catadores de materiais recicláveis: lutas e conformações. Revista Katálysis, Florianópolis, v. 16, n. 2, p. 248-57, 2013.

BRAGA, N.; MACIEL, R. Desafios e contradições de um projeto solidário: o caso da associação de catadores de materiais recicláveis. Interações, Campo Grande, MS, v. 19, n. 3, p. 557-68, 2018.

BRANDÃO, H. H. N. Introdução à análise do discurso. Campinas: Editora Unicamp, 2002.

BASTOS, H. M.; ARAÚJO, G. C. Cidadania, empreendedorismo social e economia solidária no contexto dos catadores cooperados de materiais recicláveis. Revista Capital Científico-Eletrônica, v.13, n.4, p.62-79, 2015.

CARDOSO, M. B. R. A Asmare e seus parceiros públicos e privados: uma rede de cooperação para a geração de trabalho e renda. 2003. Dissertação (Mestrado em Administração) - Pontifícia Universidade Católica de Minas Gerais, Belo Horizonte, MG, 2003.

CARDOZO, B. D.; ARAÚJO, G. C.; MARIANI, M. A. Comprometimento organizacional em uma cooperativa de reciclagem. Interações, Campo Grande, v. 18, n. 3, p. 107-20, 2017.

COMISSÃO EMPRESARIAL PARA A RECICLAGEM [CEMPRE]. Review. CEMPRE: São Paulo, 2015. Disponível em: https://cempre.org.br/wp-content/uploads/2020/11/CEMPRE-Review2019.pdf. Acesso em: 19 jan. 2019.

COSTA, C. M.; PATO, C. A constituição de catadores de material reciclável: a identidade estigmatizada pela exclusão e a construção da emancipação como forma de transcendência. In: PEREIRA, B. C. J.; GOES, F. L. Catadores de materiais recicláveis: um encontro nacional. Rio de Janeiro: IPEA, 2016. p. 99-122.

DIAS, S. M. Construindo a cidadania: avanços e limites do projeto de coleta seletiva em parceria com a Asmare. 2002. Dissertação (Mestrado em Geografia) - Universidade Federal de Minas Gerais, Belo Horizonte, MG, 2002.

FERRAZ, D. L. S.; BURIGO, L. A gestão em empreendimentos populares e o processo de trabalho no setor de reciclagem. In: ENCONTRO DE ESTUDOS ORGANIZACIONAIS DA ANPAD, 4., maio, 2012, Curitiba. Anais [...]. Rio de Janeiro: ANPAD, 2012.

FERRAZ, D. L. S.; MUELLER, R. R. Assistencialismo e empreendimentos populares de trabalho: relações para a erradicação da pobreza? Gestão e Sociedade, Belo Horizonte, v. 7, n. 17, p. 186-219, 2013.

GONZÁLEZ REY, F. Pesquisa qualitativa e subjetividade: os processos de construção da informação. São Paulo: Editora Thomson, 2005.

INSTITUTO DE PESQUISA ECONÔMICA APLICADA [IPEA]. A organização coletiva de catadores de material reciclável no Brasil: dilemas e possibilidades sob a ótica da economia solidária. Brasília: IPEA, 2017.

INSTITUTO DE PESQUISA ECONÔMICA APLICADA [IPEA]. Situação social das catadoras e dos catadores de material reciclável e reutilizável. Brasília: IPEA, 2013. 
JACOBI, P.; TEIXEIRA, M. A. C. Criação do capital social: o caso da Asmare. Cadernos de gestão pública e cidadania, São Paulo, v. 2, n. 2, 1997.

MAGALHÃES, B. J. Liminaridade e exclusão: caracterização permanente ou transitória das relações entre os catadores e a sociedade brasileira? In: PEREIRA, B. C. J.; GOES, F. L. Catadores de materiais recicláveis: um encontro nacional. Rio de Janeiro: IPEA, 2016. p. 123-50.

PEREIRA, M. C. G.; TEIXEIRA, M. A. C. A inclusão de catadores em programas de coleta seletiva: da agenda local à nacional. Cadernos EBAPE. BR, Rio de Janeiro, v. 9, n. 3, p. 895-913, 2011.

SANT'ANA, D.; METELLO, D. Reciclagem e inclusão social no Brasil: balanço e desafios. In: PEREIRA, B. C. J.; GOES, F. L. Catadores de materiais recicláveis: um encontro nacional. Rio de Janeiro: IPEA, 2016.

SILVA, C. M. Trabalho, cidadania e reconhecimento: a rede Cataunidos e o protagonismo sociopolítico de catadores de recicláveis na RMBH. 2014. Tese (Doutorado em Ciências Sociais) - Pontifícia Universidade Católica de Minas Gerais, Belo Horizonte, MG, 2014.

SILVA, C. L. ; BOLSON, C. R. ; FERRIGOTI, C. M. Tecnologia e inclusão social: cooperativa Catamare. Interações, Campo Grande, v. 17, n. 3, p. 516-27, 2016.

TORRES, H. R. As organizações dos catadores de material reciclável: inclusão e sustentabilidade. O caso da associação dos catadores de papel, papelão e material reaproveitável, Asmare, em Belo Horizonte, MG. 2008. Dissertação (Mestrado em Desenvolvimento Sustentável) - Universidade de Brasília, BrasíliaDF, 2008.

\section{Sobre os autores:}

Romário Rocha Sousa: Mestre em Administração pela Universidade Federal de Minas Gerais (UFMG). Bacharel em Administração pela UFMG. Professor do Instituto Federal do Norte de Minas Gerais (IFNMG). E-mail: romariorochasousa@gmail.com, Orcid: http://orcid.org/0000-0002-8208-9496

Rafael Diogo Pereira: Doutor e mestre em Administração pela Universidade Federal de Minas Gerais. Graduado em Turismo pela UFMG. Docente e orientador do Programa de Pós-Graduação em Administração da UFMG (CEPEAD/UFMG). Docente adjunto na UFMG. E-mail: rdp.ufmg@gmail.com, Orcid: http://orcid.org/0000-0002-1057-2614

Daniel Calbino: Doutor e mestre em Administração pela Universidade Federal de Minas Gerais. Graduado em Administração pela Universidade Federal de São João del-Rei. Docente e orientador do Programa de Pós-Graduação em Educação da Universidade Federal do Vale do Jequitinhonha e Mucuri (PPGED/UFVJM). Docente adjunto na Universidade Federal de São João del-Rei (UFSJ). E-mail: dcalbino@ufsj.edu.br, Orcid: http://orcid.org/0000-0001-8260-6126 